\title{
USULAN PENJADWALAN PRODUKSI PRODUK ST 37777 PT EBAKO NUSANTARA PADA DEPARTEMEN SMOOTHMILLING UNTUK MEMINIMASI MAKESPAN
}

\author{
Mellysa Asmawar, Sriyanto*) \\ Departemen Teknik Industri, Fakultas Teknik, Universitas Diponegoro \\ Jl. Prof. Soedarto, SH, Kampus Undip Tembalang, Semarang, Indonesia 50275
}

(Received: December 04, 2017/ Accepted: March 25, 2018)

\begin{abstract}
Abstrak
Proses produksi ST 37777 di PT Ebako Nusantara menggunakan jadwal yang didasarkan oleh prosesproses yang dilakukan dengan menggunakan data historis yang telah ada dari proses produksi yang telah dilakukan. PT Ebako Nusantara merupakan industri manufaktur yang bergerak di bidang furnitur yang berlokasi di Terboyo, Semarang, Jawa Tengah. Dalam proses produksi ST 37777, terdapat 11 mesin dan 16 job dimana setiap job memiliki urutan mesin yang berbeda. Penjadwalan yang ada untuk produk tipe ST 37777 dengan tipe jobshop belum menerapkan suatu ketetapan dalam penentuan waktu dan urutan pengerjaan mesin yang efektif sehingga masih banyak job yang selesai terlambat. Untuk itu diperlukan suatu penjadwalan mesin yang efektif sehingga dapat memenuhi waktu produksi pesanan sesuai dengan yang telah disepakati. Penjadwalan jobshop diperlukan untuk memaksimumkan efisiensi dan utilitas sumber daya di lantai produksi. Penentuan jadwal mesin ini bertujuan meminimasi makespan dengan menggunakan Software WINQSB modul job schedulling. Metode yang digunakan adalah metode Short Processing Time. Hasil penjadwalan menggunakan Software WINQSB diperoleh makespan menjadi 15 jam dengan hasil penjadwalan tersebut tidak ada job yang terlambat dan semua job dikerjakan berurutan. Kata Kunci: Penjadwalan Jobshop; Short Processing Time; Minimasi Makespan
\end{abstract}

\begin{abstract}
The production process of ST 37777 in PT Ebako Nusantara uses a schedule based on the processes performed using existing historical data from the production process that has been done. PT Ebako Nusantara is a manufacturing industry engaged in furnitur located in Terboyo, Semarang, Central Java. In the production process ST 37777, there are 11 machines and 16 jobs where each job has a different sequence of machines. The existing scheduling for ST 37777 type product with jobshop type has not been applied a determination in the timing and sequence of effective machine work so that many jobs are finished too late. For that required an effective engine scheduling so that it can meet the production time of orders in accordance with the agreed. Jobshop scheduling is needed to maximize efficiency and resource utilities on the production floor. Determination of this machine schedule aims to minimize the makespan using WINQSB Software job scheduling module. The method used is the method of Short Processing Time. The scheduling result using WINQSB software obtained makespan to 15 hours with scheduling result no job is late and all job done in sequence.
\end{abstract}

Keywords: Jobshop Scheduling; Short Processing Time; Makespan Minimization

\footnotetext{
*) Penulis Korespondensi.

e-mail: acamellysa@student.undip.ac.id
} 


\section{PENDAhuluan}

Perkembangan industri manufaktur semakin maju seiring dengan perkembangan zaman dan teknologi. Hal ini menyebabkan kebutuhan akan hasil yang diproduksi sesuai dengan permintaan pelanggan. Sektor industri furnitur saat ini merupakan salah satu sektor yang banyak diminati oleh banyak orang. Untuk dapat mencapai kepuasan pelanggan, maka sangat diperlukan sistem produksi yang terencana dan ada pengendalian yang baik.

PT Ebako Nusantara berdiri sejak 1996 merupakan industri manufaktur yang bergerak di bidang furnitur. Dalam proses produksi di Departemen Smoothmilling PT Ebako Nusantara membutuhkan perencanaan ulang penjadwalan produksi untuk kode produk ST 37777 karena dimensi, bahan, material, jumlah job dan mesin yang diperlukan dalam pembuatan produk berbeda dari produk tipe lain.

\section{METODE PENELITIAN}

Penelitian ini dilaksanakan selama sebulan dimulai 20 Desember 2016 hingga 20 Januari 2017 di PT. Ebako Nusantara pada Departemen Smoothmilling. Berikut adalah metode penelitian yang dilakukan :

\section{Pengumpulan Data}

Data yang digunakan dalam penelitian ini adalah waktu baku setiap job pada setiap mesin yang ada di Departemen Smoothmilling untuk produk ST 37777. Data yang diperoleh merupakan data sekunder karena datanya berupa data historis perusahaan yang telah tersusun rapi dalam sebuah arsip. (Subana, 2000). Namun jika dilihat dari jenis datanya, maka data digolongkan menjadi data kuantitatif karena informasi data yand berbentuk angka. (Riduwan, 2001).

\section{Pengolahan Data}

Bedasarkan data waktu baku setiap job pada setiap mesin pada Departemen Smoothmilling PT Ebako Nusantara diketahui tidak adanya perencanaan produksi dalam hal penjadwalan produksi seringkali menyebabkan lamanya waktu eksekusi order atau shoptime yang terkadang berbeda dengan set jadwal yang diestimasikan sebelumnya. Teknik layanan melalui prioritas penjadwalan yang selama ini diterapkan dinilai tidak cukup baik untuk mengatasi persoalan penjadwalan produksi tersebut, khususnya untuk persoalan tipe jobshop. Untuk menanggulangi masalah banyaknya produk yang terlambat pada Departemen Smoothmilling maka dilakukan perhitungan untuk meminimasi makespan menggunakan software WINQSB dengan metode Shortest Processing Time. Membuat jadwal urutan produksi dan waktu yang dibutuhkan untuk setiap job yang sesuai dan mampu meminimasi makespan.

\section{PEMBAHASAN DAN ANALISIS}

Pengolahan data dilakukan dengan menggunakan pendekatan komputasi berguna untuk membandingkan perolehan makespan dan efisiensi penjadwalan hasil komputasi dengan menggunakan algoritma heuristik pada modul penjadwalan software WINQSB.

Produk ST 37777 memiliki 16 job dengan beberapa operasi dengan waktu pengerjaan yang berbeda untuk masing masing mesin dan operasi. Daftar job dan operasi yang ada untuk produk ST 37777 serta duedate untuk setiap job ditampilkan pada Tabel 1. Mesin yang digunakan untuk setiap job ST 37777 ditampilkan pada Tabel 2.

Tabel 1. Waktu Proses Operasi Job ST 37777

\begin{tabular}{|c|c|c|c|c|c|c|c|}
\hline \multirow{2}{*}{ No } & \multirow{2}{*}{$J o b$} & \multicolumn{5}{|c|}{ Operasi (s) } & \multirow{2}{*}{ Due date } \\
\hline & & 1 & 2 & 3 & $\overline{4}$ & 5 & \\
\hline 1 & Top panel & 5004 & 4530 & & & & 5030,4 \\
\hline 2 & Side panel & 9060 & & & & & 9060 \\
\hline 3 & Leg & 1386 & 1536,8 & 1720 & 2310 & 1536,8 & 8489,6 \\
\hline 4 & Backpanel & 4530 & & & & & 4530 \\
\hline 5 & Front edge & 364 & & & & & 364 \\
\hline 6 & Side edge & 693 & 3842 & & & & 4535 \\
\hline 7 & Bottom panel & 4530 & & & & & 4530 \\
\hline 8 & Front apron & 1732 & 1039 & 1290 & & & 4061 \\
\hline 9 & Center apron & 346 & 430 & 1921 & & & 2697 \\
\hline 10 & Side apron & 2078 & 2580 & 1152,6 & & & 5810,6 \\
\hline 11 & Back apron & 1039 & 1290 & & & & 2329 \\
\hline 12 & Side rail & 2078 & 2580 & & & & 4658 \\
\hline 13 & Front drawer ( rf ) & 3842 & 3842 & 3842 & 3842 & & 15368 \\
\hline 14 & Side drawer & 1386 & 7684 & 1160 & & & 10230 \\
\hline 15 & Back drawer & 693 & 3842 & 580 & & & 5115 \\
\hline 16 & Floring & 9060 & & & & & 9060 \\
\hline
\end{tabular}


Tabel 2. Mesin yang Digunakan untuk Job ST 37777

\begin{tabular}{cccccc}
\hline \multirow{2}{*}{ Job } & \multicolumn{5}{c}{ Operasi } \\
\cline { 2 - 6 } & $\mathbf{1}$ & $\mathbf{2}$ & $\mathbf{3}$ & $\mathbf{4}$ & $\mathbf{5}$ \\
\hline 1 & 1 & 10 & & & \\
\hline 2 & 10 & & & & \\
\hline 3 & 5 & 8 & 7 & 2 & 10 \\
\hline 4 & 10 & & & & \\
\hline 5 & 5 & & & & \\
\hline 6 & 5 & 8 & & & \\
\hline 7 & 10 & & & & \\
\hline 8 & 2 & 5 & 7 & & \\
\hline 9 & 5 & 7 & 9 & & \\
\hline 10 & 5 & 7 & 9 & & \\
\hline 11 & 5 & 7 & & & \\
\hline 12 & 5 & 7 & & \\
\hline 13 & 6 & 4 & 3 & \\
\hline 14 & 5 & 8 & 11 & \\
\hline 15 & 5 & 8 & 11 & \\
\hline 16 & 10 & & & & \\
\hline
\end{tabular}

Berdasarkan data yang ada dilakukan perhitungan dengan software komputasi WINQSB version 2.0 dengan modul penjadwalan job Schedulling dengan metode SPT menghasilkan output yang ditampilkan pada Gambar 1.

Rekapitulasi hasil pengolahan data dengan modul job schedulling pada WINQSB dapat dilihat pada Tabel 3. Berdasarkan rekapitulasi hasil penjadwalan dengan software WINQSB pada Tabel 3., diperoleh flow process time setiap job yang menunjukan lama waktu untuk memproses untuk setiap job. Flow process time untuk job 1 adalah 1,4 jam, job 2 adalah 2,52 jam, job 3 adalah 10,05 jam, job 4 adalah 1,27 jam, job 5 adalah 0,1 jam, job 6 adalah 1,27 jam, job 7 adalah 1,27 jam, job 8 adalah 1,14 jam, job 9 adalah 0,75 jam, job 10 adalah 3,2 jam, job 11 adalah 0,65 jam, job 12 adalah 1,3 jam, job 13 adalah 4,267 jam, job 14 adalah 2,84 jam, job 15 adalah 1,44 jam dan job 16 adalah 2,52 jam. Untuk job dengan waktu proses terlama ada pada job 3 dengan total waktu 10,05 yaitu leg. Sedangkan job dengan waktu tersingkat ada pada job 5 dengan waktu 0,1 jam yaitu front edge. Rata-rata flow process time untuk seluruh job adalah 2,34 jam.

Durasi waktu total untuk keseluruhan job diperoleh dari penjumlahan masing-masing waktu penyelesaian (completion time) tiap job sehingga diperoleh total waktu 37,25 jam. Nilai rataan dari completion time (MC) diperoleh sebesar 2,4 jam. Berdasarkan hasil penjadwalan menggunakan software WINQSB diperoleh makespan untuk produk ST 37777 adalah sebesar 15 jam. Sehingga dari hasil tersebut dapat diketahui bahwa tidak ada job yang terlambat.

Berdasarkan data pada Tabel 1, 2, dan $\mathbf{3}$ untuk ST 37777 dapat dibuat penjadwalan untuk setiap job berdasarkan mesin yang digunakan. penjadwalan tersebut dapat dibuat Gantt Chart pada Gambar 2. 


\begin{tabular}{|c|c|c|c|c|c|c|}
\hline 05-25-2017 & Job & \begin{tabular}{|l|} 
Operation \\
\end{tabular} & \begin{tabular}{|l|} 
On Machine \\
\end{tabular} & Process Time & Start Time & Finish Time \\
\hline 1 & Job 1 & 1 & Machine 1 & 500 & $\mathbf{0}$ & 500 \\
\hline 2 & Job 1 & 2 & Machine 10 & 4530 & 22650 & 27180 \\
\hline 3 & Job 2 & 1 & Machine 10 & 9060 & 9060 & 18120 \\
\hline 4 & Job 3 & 1 & Machine 5 & 1368 & $\mathbf{0}$ & 1368 \\
\hline 5 & Job 3 & 2 & Machine 8 & 15368 & 1368 & 16736 \\
\hline 6 & Job 3 & 3 & Machine 7 & 1720 & 16736 & 18456 \\
\hline 7 & Job 3 & 4 & Machine 2 & 2310 & 18456 & 20766 \\
\hline 8 & Job 3 & 5 & Machine 8 & 15368 & 24420 & $\mathbf{3 9 7 8 8}$ \\
\hline $\mathbf{9}$ & Job 4 & 1 & Machine 10 & 4530 & 18120 & 22650 \\
\hline 10 & Job 5 & 1 & Machine 5 & 364 & 10720 & 11084 \\
\hline 11 & Job 6 & 1 & Machine 5 & 693 & 7603 & 8296 \\
\hline 12 & Job 6 & 2 & Machine 8 & 3842 & 43630 & 47472 \\
\hline 13 & Job 7 & 1 & Machine 10 & 4530 & 27180 & 31710 \\
\hline 14 & Job 8 & 1 & Machine 2 & 1732 & $\mathbf{0}$ & 1732 \\
\hline 15 & Job 8 & 2 & Machine 5 & 1039 & 8642 & 9681 \\
\hline 16 & Job 8 & 3 & Machine 7 & 1290 & 10613 & 11903 \\
\hline 17 & Job 9 & 1 & Machine 5 & 346 & 8296 & 8642 \\
\hline 18 & Job 9 & 2 & Machine 7 & 430 & 10183 & 10613 \\
\hline 19 & Job 9 & 3 & Machine 9 & 1921 & 17552 & 19473 \\
\hline 20 & Job 10 & 1 & Machine 5 & 2078 & 1368 & 3446 \\
\hline 21 & Job 10 & 2 & Machine 7 & 2580 & 3446 & 6026 \\
\hline 22 & Job 10 & 3 & Machine 9 & 11526 & 6026 & 17552 \\
\hline 23 & Job 11 & 1 & Machine 5 & 1039 & 9681 & 10720 \\
\hline $2 \mathbf{2 4}$ & Job 11 & 2 & Machine 7 & 1290 & 11903 & 13193 \\
\hline 25 & Job 12 & 1 & Machine 5 & 2078 & 5525 & 7603 \\
\hline 26 & Job 12 & 2 & Machine 7 & 2580 & 7603 & 10183 \\
\hline 27 & Job 13 & 1 & Machine 6 & 3842 & $\mathbf{0}$ & 3842 \\
\hline 28 & Job 13 & 2 & Machine 4 & 3842 & 3842 & 7684 \\
\hline 29 & Job 13 & 3 & Machine 3 & 3842 & 7684 & 11526 \\
\hline 30 & Job 13 & 4 & Machine 8 & 3842 & 47472 & 51314 \\
\hline 31 & Job 14 & 1 & Machine 5 & 1386 & 3446 & 4832 \\
\hline 32 & Job 14 & 2 & Machine 8 & 7684 & 16736 & 24420 \\
\hline 33 & Job 14 & 3 & Machine 11 & 1160 & 24420 & 25580 \\
\hline 34 & Job 15 & 1 & Machine 5 & 693 & 4832 & 5525 \\
\hline 35 & Job 15 & 2 & Machine 8 & 3842 & 39788 & 43630 \\
\hline 36 & Job 15 & 3 & Machine 11 & $\mathbf{5 8 0}$ & 43630 & 44210 \\
\hline \multirow[t]{8}{*}{37} & Job 16 & 1 & Machine 10 & 9060 & $\mathbf{0}$ & 9060 \\
\hline & Cmax = & 51314 & $\mathbf{M C}=$ & 25029.5 & $w \max =$ & 42937 \\
\hline & $\mathbf{M W}=$ & 16661.69 & $F \max =$ & 51314 & $\mathbf{M F}=$ & 25029.5 \\
\hline & $\operatorname{Lmax}=$ & 51314 & $\mathbf{M L}=$ & 25029.5 & $\operatorname{Emax}=$ & $\mathbf{0}$ \\
\hline & $\mathbf{M E}=$ & $\mathbf{0}$ & $T \max =$ & 51314 & $\mathbf{M T}=$ & 25029.5 \\
\hline & $\mathbf{N T}=$ & 16 & WIP = & 7.8043 & $\mathbf{M U}=$ & 0. 2372 \\
\hline & $\mathbf{T J C}=$ & $\mathbf{0}$ & TMC = & $\mathbf{0}$ & $\mathbf{T C}=$ & $\mathbf{0}$ \\
\hline & Solved by & Primary & Heuristic $=$ & MWKR & TieBreaker = & Pandom \\
\hline
\end{tabular}

Gambar 1. Output pada WINQSB untuk ST 37777 
Tabel 3. Hasil Penjadwalan Modul Job Schedulling

\begin{tabular}{|c|c|c|c|c|}
\hline No & Job & Operation & On Machine & Process Time (s) \\
\hline 1 & Job 1 & 1 & Machine 1 & 8 \\
\hline 2 & Job 1 & 2 & Machine 10 & 76 \\
\hline 3 & Job 2 & 1 & Machine 10 & 151 \\
\hline 4 & Job 3 & 1 & Machine 5 & 23 \\
\hline 5 & Job 3 & 2 & Machine 8 & 256 \\
\hline 6 & Job 3 & 3 & Machine 7 & 29 \\
\hline 7 & Job 3 & 4 & Machine 2 & 39 \\
\hline 8 & Job 3 & 5 & Machine 8 & 256 \\
\hline 9 & Job 4 & 1 & Machine 10 & 76 \\
\hline 10 & Job 5 & 1 & Machine 5 & 6 \\
\hline 11 & Job 6 & 1 & Machine 5 & 12 \\
\hline 12 & Job 6 & 2 & Machine 8 & 64 \\
\hline 13 & Job 7 & 1 & Machine 10 & 76 \\
\hline 14 & Job 8 & 1 & Machine 2 & 29 \\
\hline 15 & Job 8 & 2 & Machine 5 & 17 \\
\hline 16 & Job 8 & 3 & Machine 7 & 22 \\
\hline 17 & Job 9 & 1 & Machine 5 & 6 \\
\hline 18 & Job 9 & 2 & Machine 7 & 7 \\
\hline 19 & Job 9 & 3 & Machine 9 & 32 \\
\hline 20 & Job 10 & 1 & Machine 5 & 35 \\
\hline 21 & Job 10 & 2 & Machine 7 & 43 \\
\hline 22 & Job 10 & 3 & Machine 9 & 192 \\
\hline 23 & Job 11 & 1 & Machine 5 & 17 \\
\hline 24 & Job 11 & 2 & Machine 7 & 22 \\
\hline 25 & Job 12 & 1 & Machine 5 & 35 \\
\hline 26 & Job 12 & 2 & Machine 7 & 43 \\
\hline 27 & Job 13 & 1 & Machine 6 & 64 \\
\hline 28 & Job 13 & 2 & Machine 4 & 64 \\
\hline 29 & Job 13 & 3 & Machine 3 & 64 \\
\hline 30 & Job 13 & 4 & Machine 8 & 64 \\
\hline 31 & Job 14 & 1 & Machine 5 & 23 \\
\hline 32 & Job 14 & 2 & Machine 8 & 128 \\
\hline 33 & Job 14 & 3 & Machine 11 & 19 \\
\hline 34 & Job 15 & 1 & Machine 5 & 12 \\
\hline 35 & Job 15 & 2 & Machine 8 & 64 \\
\hline 36 & Job 15 & 3 & Machine 11 & 10 \\
\hline 37 & Job 16 & 1 & Machine 10 & 151 \\
\hline
\end{tabular}




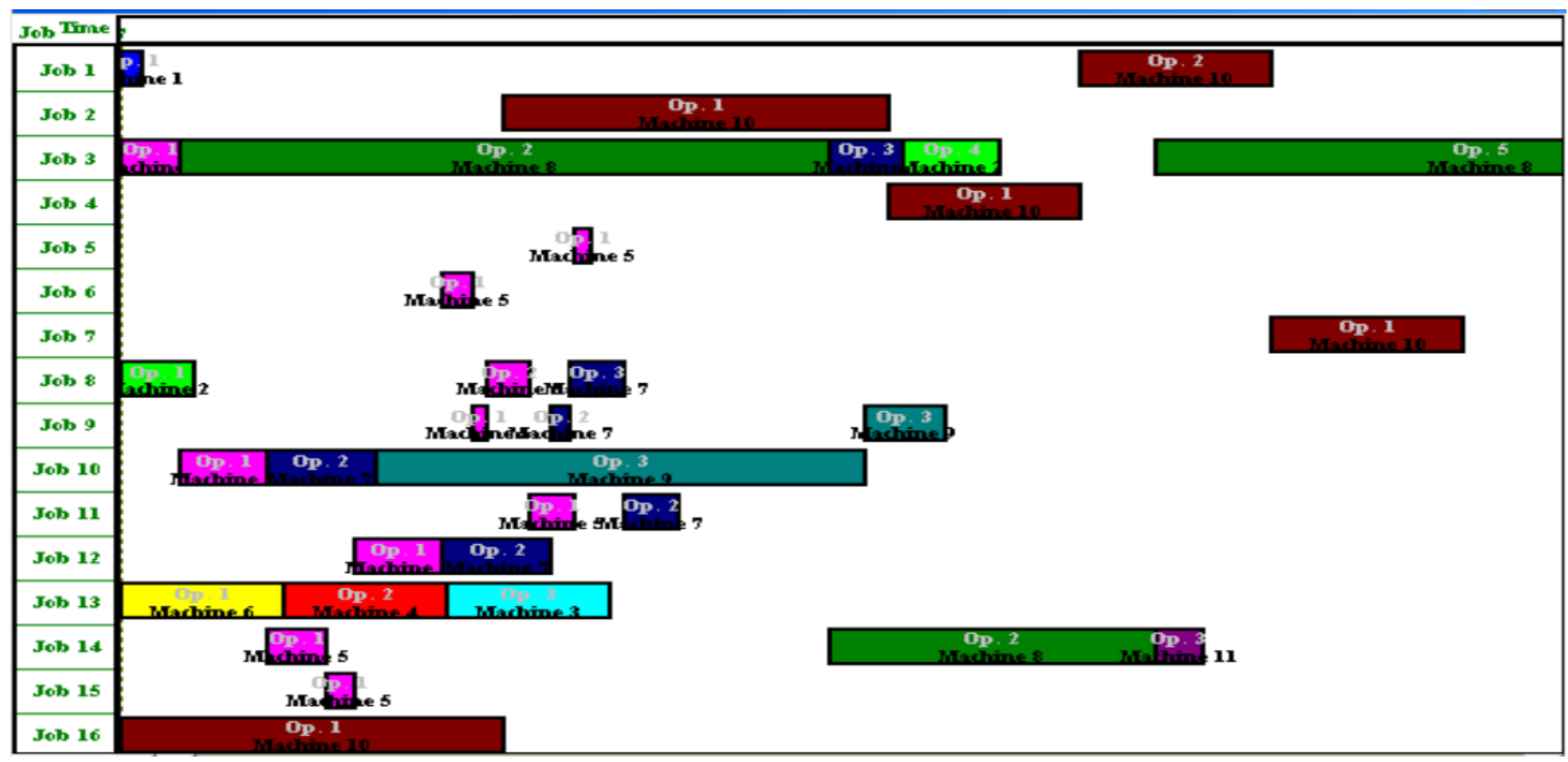

Gambar 2. Penjadwalan Untuk Setiap Job Berdasarkan Mesin

\section{KESIMPULAN}

Setelah melakukan penelitian ini, ada beberapa hal yang dapat disimpulkan, yaitu penjadwalan yang telah dilakukan oleh PT Ebako Nusantara adalah penjadwalan pada produk ST 37777 dengan sistem lama yang tergantung pada jumlah komponen dengan ketentuan prodek yang datang lebih awal yang lebih dahulu. Sedangkan penjadwalan dengan menggunakan software WINQSB dengan metode Shortest Processing Time dilakukan dengan waktu proses paling kecil dan setelah 1 proses selesai dikerjakan, maka akan dilanjutkan dengan proses berikutnya. Dengan menggunakan software WINQSB makespan untuk menyelesaikan proyek ST 37777 adalah 15 jam.

Penjadwalan mesin dengan metode Shortest Processing Time memiliki pengurutan pekerjaan (job sequencing) dan waktu yang lebih cepat dan lebih jelas dibandingkan dengan penjadwalan yang dilakukan dengan pengurutan manual oleh perusahaan. Karena selain memiliki waktu kerja yang lebih pendek, penjadwalan dengan metode SPT ini menghasilkan efektifitas penggunaan mesin dengan mempersingkat waktu menganggur mesin.

\section{DAFTAR PUSTAKA}

Baker, Kenneth R, 1974. Introducing To Sequencing and Scheduling . John Wiley \& Sons. New York.
Fitriana, Ines Candra, 2016. Analisis Penjadwalan Produk PT Eksotika Logam Bali (Deco Bali) Dengan Minimasi Makespan, Laporan Kerja Praktek, Universitas Diponegoro

Muluk, Asmuliardi. 2008. Penjadwalan Job Shop Dengan Kriteria Minimasi Makespan (Studi Kasus Di Workshop II PT. Semen Padang) Jurnal Ilmiah Teknik Industri, Universitas Andalas.

Narasimhan, Seetharama L.et al. 1994. Production Planning \& Inventory Control. Prentice-Hall, International Inc : New Jersey: USA.

Render, Barry dan Jay Heizer. 2009. Operations Management 9th edition. Salemba Empat : Jakarta.

Riduwan. 2001. Dasar - Dasar Statistika. Bandung : Alfabeta

Sayuti, Bin Komarudin, 2011. https://staff.blog.ui.ac.id/komarudin74/job-shopscheduling-penjadwalan-job-shop/ (diakses pada 13 Desember 2017)

Subana. 2000. Statistik Pendidikan. Bandung : Pustaka Setia 